This PDF is a selection from an out-of-print volume from the National Bureau of Economic Research

Volume Title: Concentrated Corporate Ownership

Volume Author/Editor: Randall K. Morck, editor

Volume Publisher: University of Chicago Press

Volume ISBN: 0-226-53678-5

Volume URL: http://www.nber.org/books/morc00-1

Conference Date: May 31-June 1, 1998

Publication Date: January 2000

Chapter Title: II. THE LAW AND CONCENTRATED CORPORATE OWNERS

8. Adverse Selection and Gains to Controllers in Corporate Freezeouts

Chapter Author: Lucian Arye Babchuk, Marcel Kahan

Chapter URL: http://www.nber.org/chapters/c9011

Chapter pages in book: (p. $247-264)$ 


\title{
Adverse Selection and Gains to Controllers in Corporate Freezeouts
}

\author{
Lucian Arye Bebchuk and Marcel Kahan
}

An important element in the governance scheme of a corporation is its ownership structure. Most publicly traded companies in the United States have a dispersed ownership structure: no single shareholder owns sufficient shares to control the company. A substantial minority of companies, however, have a controlling shareholder.' A controlling shareholder exercises powers that are available neither to the dispersed shareholders in a company without a controlling shareholder nor to the minority shareholders in a company with a controlling shareholder. As the Delaware Supreme Court recently summarized, a controlling shareholder can "(a) elect directors; (b) cause a break-up of the corporation; (c) merge it with another company; (d) cash-out the public stockholders; (e) amend the certificate of incorporation; (f) sell all or substantially all of the corporate assets; or (g) otherwise alter materially the nature of the corporation and the public stockholders' interests." 2

Lucian Arye Bebchuk is the William J. Friedman and Alicia Townsend Friedman Professor of Law, Economics, and Finance at Harvard Law School and a research associate of the National Bureau of Economic Research. Marcel Kahan is professor of law at the New York University School of Law.

An earlier version of this paper was circulated as "The 'Lemons Effect' in Corporate Freezeouts," Discussion Paper no. 248, John M. Olin Center for Law, Economics, and Business, Harvard Law School. For helpful comments and conversations, the authors are grateful to Barry Adler, Bill Allen, J. P. Benoit, Bernie Black, John Coates, Jeff Gordon, Zohar Goshen, Ehud Kamar, Lewis Kornhauser, Bo Li, Brandon Vergas, workshop participants at the American Law and Economics Association meeting, Hebrew University, Interdisciplinary Center (Herzliah), Tel-Aviv University, and the NBER conference. For financial support, Lucian Bebchuk thanks the National Science Foundation and the John M. Olin Center for Law, Economics, and Business, and Marcel Kahan thanks the Filomen D'Agostino and Max E. Greenberg Research Fund at the New York University School of Law.

1. For example, Barclay and Holderness (1989) report that, in a randomly chosen sample of 394 publicly traded companies in 1986,20 percent of the companies had a shareholder with a block exceeding 35 percent of equity.

2. Paramount Communications Inc. v. QVC Network Inc., 637 A.2d 34 (Del. 1994). 
This paper focuses on one of these enumerated powers-the power to cash out, or "freeze out," the minority shareholders. Such freezeouts are accomplished by a merger with a corporation wholly owned by the controlling shareholder. After the freezeout, the controlling shareholder emerges as the sole equityholder of the company. In most states, mergers require the approval of the company's board of directors as well as of holders of a majority of outstanding shares. ${ }^{3} \mathrm{~A}$ shareholder who holds a majority of shares can effectively control both approval prongs and thus unilaterally set the price at which minority shareholders are frozen out (the "freezeout price"). The power to freeze out the minority shareholders on potentially unfavorable terms is one of several ways through which a controlling shareholder can derive benefits from control to the exclusion of, and at the expense of, the minority shareholders. ${ }^{4}$

While the power of the controlling shareholder to freeze out the minority shareholders and to set the freezeout price is unfettered, minority shareholders have some remedies if they feel that the freezeout price has been set too low. First, they can seek a judicial appraisal of their shares, in which case they will receive the value of their shares as assessed by the court (rather than the freezeout price). ${ }^{5}$ Second, in some circumstances, minority shareholders can seek judicial review of the freezeout merger under the "entire fairness" standard, in which case the court will award them damages if the value of the minority shares, as assessed by the court, exceeds the freezeout price. ${ }^{6}$ While these two types of proceedings differ in certain respects, they both rely on a judicial assessment of the value of minority shares. ${ }^{7}$ Both types of proceedings can, in principle-if the

3. See, e.g., Delaware General Corporation Law (Del. GCL), sec. 251; Revised Model Business Corporation Act (RMBCA), sec. 11.03.

4. In addition to freezeouts, a controlling shareholder can engage in self-dealing transactions with the controlled company, usurp corporate opportunities, structure the company's dividend policy to fit her tax situation or cash-flow needs, or sell "control" to another shareholder. For formal models of sales of corporate control, see Bebchuk (1994) and Kahan (1993).

5. See, e.g., Del. GCL, sec. 262(b); RMBCA, sec. 13.02 .

6. See Weinberger v. UOP, Inc., 457 A.2d 701, 714-15 (Del. 1983) (discussing the entire fairness standard in freezeouts and its relations to appraisal rights); RMBCA, sec. 13.02(b) (remedies beyond appraisal rights are available if transaction is fraudulent or unlawful). At least in Delaware, a freezeout merger where the price is unilaterally set by the controlling shareholder appears to allow minority shareholders to bring an entire fairness action. See Cede \& Co. v. Technicolor, Inc., C.A. Nos, 7129 and 8358, slip op. at 15, 16 (Del. Ch. Jan. 13, 1987), rev'd on other grounds, 542 A.2d 1182 (Del. 1988) (appraisal is not an exclusive remedy where a breach of fiduciary duty is involved); Jedwab v. MGM Grand Hotels, Inc., 509 A.2d 584, 594 (Del. Ch. 1986) (courts apply entire fairness standard when a controlling shareholder "effectuate[s] a transaction in which [it has] an interest that diverges from that of the corporation or the minority shareholders").

7. In general, the methodology for determining the value of minority shares is the same in entire fairness and appraisal proceedings. See Rosenblatt v. Getty Oil Co., 493 A.2d 929, 940 (Del. 1985); but see Cede \& Co. v. Technicolor, Inc., 634 A.2d 345, 371 (Del. 1993) (noting that measure of loss under the entire fairness standard is "not necessarily" limited to the 
assessment is accurate - protect minority shareholders from being denied the "no-freezeout value"--the value that their shares would have in the absence of the considered freezeout. ${ }^{8}$

This paper identifies and analyzes a fundamental problem involved in the regulation of corporate freezeouts. When deciding whether to effect a freezeout, a controlling shareholder might take advantage of its private information. When freezeouts take place under conditions of asymmetric information, we demonstrate, allowing controlling shareholders to effect a freezeout at a price equal or close to the pretransaction price of minority shares would enable controlling shareholders to effect such transactions on favorable terms and to extract in this way substantial private benefits of control.

As this paper shows, courts face some difficult, inherent problems in trying to reach an accurate assessment of the no-freezeout value. These problems arise from the fact that controllers, who decide whether to effect a freezeout, are also likely to have private information concerning the firm's value. As a result, the prefreezeout market price of minority shares, which is often used by courts in the assessment of the minority shares' nofreezeout value, is likely to underestimate the no-freezeout value.

Our analysis is organized as follows. Section 8.1 contains a short discussion of the use of market prices to assess the value of minority shares in freezeouts and a numerical example illustrating the adverse selection effect that results from such use. Section 8.2 contains a game-theoretic model demonstrating that, if a controlling shareholder can freeze out the minority shareholders at the prefreezeout market price, that market price will reflect the per share value of the company assuming that the controlling shareholder has the worst possible private information about the value of the company. A right to freeze out the minority shareholders at such a market price would therefore confer substantial profits on the controlling shareholder. The model uses several simplifying assumptions, but our work in progress (Bebchuk and Kahan 1999) suggests that its main result--that the presence of private information enables a controlling shareholder to gain systematically at the expense of minority shareholders holds in a more general setting. Section 8.3 provides a concluding discussion that

difference between the appraised value and the price offered in the merger since the chancellor has discretion to award rescissory damages if appropriate).

8. There is a large literature on whether providing minority shareholders in a freezeout with the no-freezeout value is enough or whether the standard to which they are entitled should be higher. For example, in two classic articles, Brudney and Chirelstein $(1974,1978)$ argued that minority shareholders should be given the no-freezeout value plus a fraction of the gains created by the freezeout. And Coates (1999) recently argued that minority shareholders in a freezeout should get their pro rata fraction of the company's value--including their pro rata fraction of the controller's existing private benefits of control. Our focus in this paper is on problems with the protection of minority shareholders that arise from problems of estimation, even if one assumes, as many courts do, that minority shareholders are entitled only to the no-freezeout value of their shares. 
reports on some of the findings of our work in progress and considers the implications of our model for the controlling shareholder's incentive to pursue investment projects and to reveal information.

\subsection{The Use of Market Prices in Freezeouts}

For an economist, a natural approach in determining the value of the minority shares is to rely on the market price of those shares prior to the freezeout. Economists generally believe that market prices provide the best estimate of the value of a share that can be formed on the basis of publicly available information - or at least a much better estimate than the one that a judge may arrive at after listening to conflicting, and undoubtedly self-serving, testimony of experts hired by the controlling and the minority shareholders. Indeed, several scholars have proposed that courts use the market price as the measure of the value of the minority shares in a freezeout. ${ }^{9}$ And courts presently look at the market price as an important, although not the exclusive, factor in appraising minority shares. ${ }^{10}$

As we show below, however, there is a fundamental flaw in using market prices to measure the value of minority shares in a freezeout. The very power of a controlling shareholder to freeze out the minority shares-and to set the freezeout price equal to the prefreezeout market price--will depress the prefreezeout market price of the minority shares. As a result, the prefreezeout market price of minority shares will be substantially below the expected "intrinsic" value of the minority shares absent a freezeout. ${ }^{11}$ This is the case even if - in fact, especially if - capital markets are informationally efficient and fully process all publicly available information. Thus, the prefreezeout market price is an unreliable guide for courts in appraising minority shares.

The reason for the discrepancy between the market price and the expected "intrinsic" value of the minority shares is that the controlling

9. See Hermalin and Schwartz (1996), which presents a model not including asymmetric information and argues that awarding the prefreezeout market price in an appraisal proceeding creates efficient incentives to invest.

10. For examples in which market value plays a significant role in valuation, see Genesco, Inc. v. Scolaro, 871 S.W.2d 487 (Tenn. Ct. App. 1993); Mc Cauley v. Tom Mc Cauley \& Son, Inc., 724 P.2d 232 (N.M. Ct. App. 1986); Friedman v. Beway Realty Corp., 638 N.Y.S.2d 399 (Ct. App. 1995); In re Glosser Brothers, 555 A.2d 129 (Pa. Super. Ct. 1989); In re Valuation of Common Stock of Libby, McNeill \& Libby, 406 A.2d 54 (Me. 1979); Chokel v. First National Supermarkets, Inc., 660 N.E.2d 644 (Mass. 1986); and Hernando Bank v. Huff, 609 F. Supp. 1124 (N.D. Miss. 1985). Indeed, market value is sometimes the most significant factor in determining fair value in appraising minority shares; see, e.g., Armstrong v. Marathon Oil, 513 N.E.2d 776 (Ohio 1987). Since U.S. courts consider the prefreezeout market price as only one of several possible factors determining the fair price, freezeout prices in the United States can and commonly do exceed the prefreezeout market price. Our model shows why it is sensible for courts not to give conclusive weight to the prefreeze out market price.

11. We use the term expected "intrinsic" value to refer to the expected value of minority share if a freezeout is not possible. 
shareholder's power to effect a freezeout creates an adverse selection effect that depresses the market price. ${ }^{12}$ A controlling shareholder will generally have private information about the value of the company that is not available to the public. Absent the possibility of forcing a freezeout, such private information would cause the market price to be inaccurate but would not cause it to be systematically biased: ${ }^{13}$ the market price may sometimes be too high or too low but would still constitute the best estimate of the value of the minority shares that can be formed on the basis of all public information. But, if the controlling shareholder has the power to freeze out the minority shareholders by paying them the prefreezeout market price, she will use that power strategically to effect a freezeout only if her private information indicates that the value of the minority shares is above their market price. This strategic use of the power to effect a freezeout results in an adverse selection effect that causes the market price of minority shares to spiral downward.

Assume, for example, that the per share value of XYZ Corporation can range from $\$ 100$ to $\$ 200$. On the basis of public information, any value in this range is equally likely. The expected "intrinsic" value of a share of XYZ Corporation is thus $\$ 150$. The controlling shareholder, however, knows the exact value of the company. The controlling shareholder can freeze out the minority shareholders at the market price. If she does not effect a freezeout, $\mathrm{XYZ}$ will be liquidated, and minority shareholders will receive their proportional interest.

If a freezeout were not possible, the market price of an $\mathrm{XYZ}$ share would be $\$ 150$ - the value that the minority shareholders expect to receive on XYZ's liquidation. Now, however, consider the effect of the power to effect a freezeout at the market price. To be in equilibrium, the market price must be equal to the average amount that the minority shareholders receive in a freezeout or on XYZ's liquidation. Let us consider first whether $\$ 150$ can remain the equilibrium market price. At that price, the controlling shareholder will effect a freezeout if she knows that XYZ's value is above $\$ 150$ per share and will not effect a freezeout if she knows that the value of an XYZ share is below $\$ 150$. Each possibility is equally

12. See Akerlof (1970), Other commentators have also suggested that the market price for minority shares will be depressed. These commentators, however, intimate that the depressed price is due to information inefficiencies or to expectations of self-dealing (Brudney and Chirelstein 1974, 1978). By contrast, we show that the market price is depressed even if the market price is set in a rational expectations equilibrium and the controlling shareholder does not derive private control benefits from self-dealing or, for that matter, from any source other than the power to freeze out the minority shares.

13. Even absent a freezeout, the controlling shareholder can buy shares at the market price in a regular market transaction. Freezeouts, however, create greater possibility for insider trading. First, in a regular market transaction, the minority shareholders can protect themselves by not selling, at least not at times when they suspect that the controlling shareholder has a lot of private information. Second, the controlling shareholder can buy only a limited number of shares before her purchases are noticed and the market price increases. 
likely, and, in the latter case, the minority shareholders would expect to receive $\$ 125$ on XYZ's liquidation. ${ }^{14}$ The expected value of the minority shares (given the possibility of a freezeout) is $\$ 137.50$ per share-and $\$ 150$ is therefore not an equilibrium market price.

Alas, for similar reasons, $\$ 137.50$ is not an equilibrium market price either. The controlling shareholder will effect a freezeout if XYZ's value is above $\$ 137.50$ per share (62.5 percent probability), and, if there is no freezeout, the minority shareholders expect to receive $\$ 118.75$ on XYZ's liquidation. The expected value of the minority shares is then $\$ 130.47 \mathrm{per}$ share-and $\$ 137.50$ is not an equilibrium price. But, at a market price of $\$ 130.47$, a freezeout will occur if XYZ's value exceeds $\$ 130.47$, and, absent a freezeout, minority shareholders expect to receive $\$ 115.24$. The expected value of the minority shares is, thus, $\$ 125.83$ per share $(\$ 130.47 \times 69.53$ percent $+\$ 115.24 \times 30.47$ percent), and so on.

Following this spiral downward, it turns out that the highest equilibrium price is $\$ 100$ - the lowest possible value of an $\mathrm{XYZ}$ share. For any market price above $\$ 100$, minority shareholders will sometimes receive the market price (if the controlling shareholder knows that XYZ's value exceeds the market value) and sometimes less (if she knows that XYZ's value is less than the market value)-meaning that they receive, on average, less than the market price per share. As a consequence, no market price above $\$ 100$ is an equilibrium. If the market price is $\$ 100$, however, the controlling shareholder will always effect a freezeout (or be indifferent if XYZ's value is exactly $\$ 100$ per share), and minority shareholders always receive $\$ 100$.

As the example suggests, the power to freeze out the minority shares can be an important source of private benefits that a controlling shareholder gains at the expense of minority shareholders. The ability to use private information to gain in a freezeout-and, importantly, the market's expectation that a controlling shareholder will use private information in this fashion-generates benefits in addition to, and independent of, any private benefits that a controlling shareholder gains from self-dealing, salaries, etc.

\subsection{A Model of Freezeouts under Asymmetric Information}

\subsubsection{The Framework of Analysis}

Shares of the company are held by one controlling shareholder and a large number of minority shareholders. Let $Y$ be the value of the company's equity and $\alpha<.5$ be the fraction of shares held by the minority shareholders. Let $n$ be the number of outstanding shares of the company.

14. Since any per share value between $\$ 100$ and $\$ 200$ is equally likely, the expected value conditional on the value being below a certain level $\$ X$ (with $\$ X$ being between $\$ 100$ and $\$ 200$ ) is halfway between $\$ X$ and $\$ 100$. The expected value conditional on the value being below $\$ 150$ is thus $\$ 125$. 
At $t=1$, a minority shareholder has to sell one share for liquidity reasons. The sale (market) price is established by an English auction among $m$ bidders with $m \geq 2$, and $P$ is the market price times the number of outstanding shares. Bidders do not own any other shares of the company. Bidders do not know the exact value of $Y$ but do know that $Y$ is distributed in $\left[Y_{L}, Y_{H}\right]$ with an expected value of $\bar{Y}$. At $t=1$, the controlling shareholder derives private control benefits $B \geq 0$ from her control. The aggregate expected value of the company to the controlling shareholder and the minority shareholders is thus $\bar{V}=\bar{Y}+B$.

At $t=2$, the controlling shareholder receives a signal $s$ regarding the value of $Y$ on the basis of which the controlling shareholder forms $\bar{Y}_{s}$ as an unbiased estimate of $Y$. Without loss of generality, assume that $s$ is distributed in $[0,1]$ with $\bar{Y}_{i} \geq \bar{Y}_{j}$ for $i>j$. In the "no possibility of a freezeout" case, no further action occurs at $t=2$. In the "possibility of a freezeout" case, the controlling shareholder has the right to freeze out the minority shares by paying a freezeout price per share equal to the market value per share.

At $t=3, Y$ becomes known, the company is liquidated, and $Y$ is distributed pro rata to its (then) shareholders.

For simplicity, assume that the discount rate is zero, that all shareholders are risk neutral, that there are no transaction costs in trading shares or effecting a freezeout, and that the value of $B$ is known. Further assume that a freezeout has no effect on the values of $Y$ and $B$.

\subsubsection{The Value of Minority Shares in a Regime without Freezeouts}

Proposirion 1. If the controlling shareholder does not have the power to effect a freezeout, the equilibrium market price of the minority shares is $\bar{Y}$ l $n$; that is, $P=\bar{Y}$.

Proof. The market price is set by bidders' bidding strategies at $t=1$. In an English auction with symmetric information, a bidder $k$ 's strategy is defined by $x_{k}$, the highest amount the bidder is willing to bid up to (if necessary) for one share. It is a dominant strategy for each bidder to set $x$ to $\bar{Y} / n$.

Let $\hat{x}$ be the highest $x$ chosen by all bidders other than bidder $k$. Bidder $k$ 's payoff will depend on the values of $x_{k}$ and $\hat{x}$. For any $x_{k}<\hat{x}$, bidder $k$ will lose the auction, and its payoff is zero. For $x_{k}>\hat{x}$, bidder $k$ will win and purchase the share at $\hat{x}+\varepsilon$, with $\varepsilon$ having an infinitesimal positive value. For $x_{k}=\hat{x}$, the winning bidder is randomly determined; that is, bidder $k$ will either lose or purchase the share for $\hat{x}$.

For $\hat{x}<\bar{Y} / n$, bidder $k$ 's expected profits are maximized by purchasing the share at $\hat{x}+\varepsilon$, that is, by setting $x_{k}>\hat{x}$. For $\hat{x}>\bar{Y} / n$, bidder $k$ 's expected profits are maximized by not purchasing the share, that is, by setting $x_{k}<\hat{x}$. For $\hat{x}=\bar{Y} / n$, bidder $k$ is indifferent between not purchasing the share and purchasing the share for $\bar{Y} / n$ and maximizes its profits by setting $x_{k} \leq \hat{x}$. 
The only value of $x_{k}$ that maximizes bidder $k$ 's profits in all three cases is $x_{k}=\bar{Y} / n$. Any value $x_{k}<\bar{Y} / n$ fails to maximize bidder $k$ 's profits for some $\hat{x}<\bar{Y} / n$; any value $x_{k}>\bar{Y} / n$ fails to maximize bidder $k$ 's profits for some $\hat{x}>\bar{Y} / n$. Setting $x_{k}=\bar{Y} / n$ is, thus, the weakly dominant strategy for bidder $k$. By the same rationale, setting $x=\bar{Y} / n$ is the dominant strategy for any other bidder.

\subsubsection{The Value of Minority Shares in a Regime with Freezeouts}

If a freezeout is possible, the equilibrium market price is determined by the strategic interactions among the bidders and between the bidders and the controlling shareholder:

Proposition 2. The only set of Nash equilibria in undominated strategies results in $P=\bar{Y}_{0}$.

Proof. The proof of proposition 2 follows from the following lemmas.

LEMMA 1. The controlling shareholder has two dominant strategies (with $P$ determined by the bidders' strategies): (1) effect a freezeout if and only if $\bar{Y}_{s} \geq P$; and (2) effect a freezeout if and only if $\bar{Y}_{\mathrm{s}}>P$.

The controlling shareholder's expected profit from effecting a freezeout is $\bar{Y}_{s}-P$, and the controlling shareholder's expected profit from not effecting a freezeout is zero. For $\bar{Y}_{s}>P$, the controlling shareholder maximizes its expected profit by effecting a freezeout; for $\bar{Y}_{s}<P$, the controlling shareholder maximizes its expected profit by not effecting a freezeout; for $\bar{Y}_{s}=P$, the controlling shareholder is indifferent between effecting and not effecting a freezeout. Any other strategy is dominated by these two strategies as they would entail either the possibility of effecting a freezeout when not effecting a freezeout maximizes expected profits or not effecting a freezeout when effecting a freezeout maximizes expected profits.

LeMma 2. For any bidder, setting $x<\bar{Y}_{0} / n$ is weakly dominated by setting $x=\bar{Y}_{0} / n$.

Bidder $k$ 's bid matters to bidder $k$ only if the controlling shareholder does not effect a freezeout and if $x_{k} \geq \hat{x}$. (Otherwise, bidder $k$ makes profits of zero regardless of its bid.) Assume, therefore, that $\hat{x} \leq \bar{Y}_{0} / n$ and that the controlling shareholder does not effect a freezeout.

If $\hat{x}=\bar{Y}_{0} / n$, setting $x_{k}=\bar{Y}_{0} / n$ means that bidder $k$ will sometimes buy a share for $\bar{Y}_{0} / n$. The payoff from buying a share for $\bar{Y}_{0} / n$ is $Y / n-$ $\bar{Y}_{0} / n \geq 0$ and thus dominates the payoff from setting $x_{k}<\bar{Y}_{0} / n$ and not buying a share (which is always zero). (Recall that, in assessing the dominance of strategies, one does not assume that the controlling shareholder plays its dominant strategy.)

If $\hat{x}<\bar{Y}_{0} / n$, setting $x_{k}>\hat{x}$ means that bidder $k$ will buy a share for $\hat{x}+$ $\varepsilon$, with a payoff of $Y / n-(\hat{x}+\varepsilon)>0$. This payoff dominates the payoff from setting $x_{k} \leq \hat{x}$. Setting $x=\bar{Y}_{0} / n$ thus weakly dominates setting $x<\bar{Y}_{0} / n$. 
LEMMA 3. If the controlling shareholder plays one of its dominant strategies, no strategy of bidders that results in $P>\bar{Y}_{0}$ is a Nash equilibrium.

If the controlling shareholder plays one of its dominant strategies, the payoff to the winning bidder is

$$
\left\{\operatorname{prob}\left(\bar{Y}_{s} \geq P\right) \times P+\operatorname{prob}\left(\bar{Y}_{s}<P\right) \times E\left[Y \mid \bar{Y}_{s}<P\right]-P\right\} / n .
$$

This payoff is negative since $E\left[Y \mid Y_{s}<P\right]<P$. The winning bidder would thus prefer to lower its bid to below $\hat{x}$ (with a payoff of zero). The strategies are therefore not in Nash equilibrium.

LEMMA 4. The following strategy profiles are Nash equilibria: (1) each bidder sets $x=\bar{Y}_{0} / n$, and the controlling shareholder effects a freezeout if and only if $\bar{Y}_{s} \geq P$; and (2) each bidder sets $x=\bar{Y}_{0} / n$, and the controlling shareholder effects a freezeout if and only if $\bar{Y}_{s}>P$.

Both of these Nash equilibria result in $P=\bar{Y}_{0}$.

The controlling shareholder cannot profit from changing her strategy since she plays a dominant strategy. Since either a freezeout is effected or $s=0$, all bidders make zero expected profits. No bidder can thus profit from reducing his bid. No bidder can profit from raising his bid since raising one's bid results in $P>\bar{Y}_{0}$, with a negative expected payoff to the winning bidder (lemma 3 ).

Lemmas 1-3 show that the strategies of the bidders and of the controlling shareholder are undominated.

It should be noted that there are an infinite number of Nash equilibrium strategies with the features of (i) $P<\bar{Y}_{0}$ and (ii) the controlling shareholder always effecting a freezeout. (In fact, any combination of strategies with these features is in Nash equilibrium.) The strategies resulting in such Nash equilibria, however, are not undominated.

Remark. The intuition behind the result that the equilibrium market price will be equal to the worst possible expected value of the company given the controlling shareholder's set of potential signals lies in the adverse selection effect of the freezeout power. The minority shareholders receive the market price if a freezeout takes place at $t=2$. If no freezeout takes place at $t=2$, the minority shareholders can deduce that, given the information available to the controlling shareholder, the value of the minority shares is below their market price; therefore, they would expect to receive less than the market price. (They never expect to receive more than the market price.) Thus, if the market price is sufficiently high that the controlling shareholder will sometimes not pursue a freezeout, the amount that the minority shareholders expect to receive is below the market price. No such price can be in equilibrium at $t=1$. On the other hand, no price below the expected value of the company if the controlling shareholder were to receive the worst possible signal can be in equilibrium since the 
minority shareholders expect to receive at least this amount whether or not a freezeout takes place.

The degree to which $\bar{Y}_{0}$-the expected value of the company assuming that the private information of the controlling shareholder is the worst possible--differs from $\bar{Y}$ - the expected value of the company absent private information - depends on the strength of the signal received. In one extreme case, where the signal reveals the actual value of the company $\left(\bar{Y}_{s}=Y\right)$, the equilibrium price drops to $Y_{L}$. In another extreme case, where the signal conveys no information $\left(Y_{0}=Y_{1}=\bar{Y}\right)$, the equilibrium price is equal to $\bar{Y}$.

Rather than by the absolute level of private information, however, the market price is determined by the extent to which the controlling shareholder has private information regarding elements that have an adverse effect on the company's value - that is, elements that drive down the value of $\bar{Y}_{0}$ (even if they do not affect any other $\bar{Y}_{s}$ ). In other words, the market price falls with (and the controlling shareholder benefits from) a more accurate signal only if the signal is negative, not if the signal is positive. In the extreme, it is sufficient to have the market price drop to $Y_{L}$ (the lowest possible value of the company) if the controlling shareholder receives a binary signal: a perfectly accurate signal indicating that the company's value is $Y_{L}$ and a highly imprecise signal indicating only that the company's value is not $Y_{L}$.

\subsubsection{The Effect of Freezeouts on Private Control Benefits}

On the basis of propositions 1 and 2, we can calculate the respective equilibrium values of the minority shares and the control block in the absence and the presence of the possibility of a freezeout.

In a regime without freezeouts, the aggregate expected value of the minority shares is

$$
\alpha \bar{Y},
$$

and the expected value of the control block (at $t=1$ ) will be

$$
(1-\alpha) \bar{Y}+B \text {. }
$$

Relative to the respective pro rata fraction of $\bar{V}$, the value of the minority shares is

$$
\alpha \bar{V}-\alpha B,
$$

and the value of the control block is

$$
(1-\alpha) \vec{V}+\alpha B \text {. }
$$

With the possibility of a freezeout, the value of the minority shares is 


$$
\alpha \overline{Y_{0}}
$$

and the expected value of the control block (at $t=1$ ) is

$$
(1-\alpha) \bar{Y}+\alpha\left(\bar{Y}-\bar{Y}_{0}\right)+B \text {. }
$$

Relative to the respective pro rata fraction of $\bar{V}$, the value of the minority shares is

$$
\alpha \bar{V}-\alpha\left(\bar{Y}-\overline{Y_{0}}\right)-\alpha B
$$

and the value of the control block is

$$
(1-\alpha) \bar{V}+\alpha\left(\bar{Y}-\overline{Y_{0}}\right)+\alpha B \text {. }
$$

Thus, as a result of the possibility of a freezeout, the value of the minority shares decreases by

$$
\alpha\left(\bar{Y}-\overline{Y_{0}}\right),
$$

and the value of the control block increases by the same corresponding amount.

The expression $\alpha\left(\bar{Y}-\bar{Y}_{0}\right)$ represents the expected value (at $t=1$ ) of the amount that the controlling shareholder can divert from the minority shareholders by the strategic exercise of the freezeout option. This adds to other sources of private control benefits $(B)$.

\subsection{Concluding Discussion}

In this paper, we presented a simple model of corporate freezeouts where the controlling shareholder has the option to pay the prefreezeout market price to the minority shareholders. We have shown that this option has substantial value to the controlling shareholder when she has private information about the value of the company. Our work in progress preliminarily indicates that the results of the simple model discussed here are robust to several variations of the model that render the model more complex and more general. In particular, we analyze freezeout pricing rules where the freezeout price is not, or not exclusively, determined by the prefreezeout market price, we examine the case where the freezeout produces efficiency gains and losses (i.e., increases or decreases the company's value), and we extend the analysis to multiple periods where, in each period, new private information becomes available to the controlling shareholder and prior private information becomes available to the market. Although the specific results derived for the value of the minority shares and the control block vary with each of these extensions, the general result of the model-that the freezeout option can be highly valuable to the controlling shareholder-continues to hold. 
The fact that the freezeout option is valuable, and that the per share value of the minority shares is below the per share value of the control block, has important policy implications. First, since the value of the freezeout option depends on the extent of the controlling shareholder's private information, a controlling shareholder has excessive incentives (from the social perspective) to obtain private information or, equivalently, to obtain information earlier than the market. Since obtaining private information is costly, a controlling shareholder will expend excessive resources on acquiring information.

Second, once private information is obtained, the controlling shareholder has excessive incentives to withhold such information from the market. These incentives result in social losses to the extent that it is socially desirable to have a more informed market and to the extent that the controlling shareholder expends resources in actively hiding information.

Third, the desire to obtain private information skews the investments that the controlling shareholder would have the company undertake. Different investment projects provide the controlling shareholder with different levels of private information, and the controlling shareholder has an incentive to choose investment projects that yield greater private information even if the projects have a negative net present value. Moreover, as explained before, private information related to adverse developments is particularly valuable. Thus, a controlling shareholder has an incentive to have the company invest in projects that potentially $(a)$ have a substantial downside and (b) supply the controlling shareholder with private information regarding whether that downside is realized.

Finally, the presence of private control benefits (of any sort) means that a party has a socially excessive incentive to become (or remain) a controlling shareholder. This excessive incentive results in social losses of two types: the transaction costs incurred in assembling a control block of shares and the reduction in diversification benefits due to the fact that one may have to hold an undiversified portfolio in order to hold a control block in a company. Additionally, any source of private control benefits is of concern if a goal of the legal system is to ensure that all shareholders participate proportionally in the value of the company.

\section{References}

Akerlof, George. 1970. The market for "lemons": Quality uncertainty and the market mechanism. Quarterly Journal of Economics 84:488-500.

Barclay, Michael, and Clifford Holderness. 1989. Private benefits from control of public corporations. Journal of Financial Economics 25:371-95.

Bebchuk, Lucian. 1994. Efficient and inefficient sales of corporate control. Quarterly Journal of Economics 91:957-93. 
Bebchuk, Lucian, and Marcel Kahan. 1999. Freezeouts under asymmetric information. Harvard Law School. Manuscript.

Brudney, Victor, and Marvin Chirelstein. 1974. Fair shares in corporate mergers and takeovers. Harvard Law Review 88:297-346. $1354-76$.

Coates, John C., IV. 1999. "Fair value" as an avoidable rule of corporate law: Minority discounts in conflict transactions. University of Pennsylvania Law Review 147:1251-1359.

Hermalin, Benjamin, and Alan Schwartz. 1996. Buyouts in large companies. Journal of Legal Studies 25:351-70.

Kahan, Marcel. 1993. Sales of corporate control. Journal of Law, Economics, and Organization 9:368-79.

\section{Comment Paul G. Mahoney}

A fundamental problem in corporate law is how to constrain a controlling shareholder from using control to appropriate the full value of the firm. One simple method of appropriation is to "freeze out" the minority shareholders by merging the firm into one wholly owned by the controlling shareholder. Because the controlling shareholder has sufficient votes to approve the merger over the minority's objections, it can cause the merger to occur at any price it wishes. Various features of corporate law try to assure that this price is "fair" to the minority.

It is tempting to say that the best measure of the fair price is the market price of the shares prior to the merger. As Bebchuk and Kahan note, however, this does not account for the information content of the majority's desire to freeze out the minority. The majority can gain from implementing a freezeout whenever it has private information indicating that the current market value of the firm is too low. Therefore, Bebchuk and Kahan argue, the majority's failure to freeze out demonstrates that the value indicated by the private signal is less than or equal to the market price. Rational shareholders will draw an adverse inference and revalue the shares downward until either the majority effects a freezeout or the shares' value reaches the bottom of the possible range of the majority's privately known valuation.

Bebchuk and Kahan argue that this adverse selection problem has implications for legal policy. For example, it might justify judges' longstanding reluctance to recognize market prices as the best measure of the fair price in a freezeout context. More important, however, the paper implicitly challenges lawyers and economists to identify the institutional features of real-world corporations that lead to results contrary to those of the model. Freezeouts cannot have the consequences for real firms that

Paul G. Mahoney is professor of law and the Albert C. BeVier Research Professor at the University of Virginia. 
they have in Bebchuk and Kahan's model. If they did, equity markets could not exist where freezeouts are permissible.

In Bebchuk and Kahan's model, shareholders know that the entrepreneur/majority shareholder will receive a private signal regarding the firm's value, that there is a determinate lower bound to that value, and that the majority has only one opportunity to implement a freezeout (which assures that the majority's failure to freeze out at that time is a reflection of private information rather than a strategic delay meant to mislead the minority). Under those circumstances, rational shareholders will not pay more than the lower bound $\left(Y_{0}\right)$ if freezeouts are permissible. As a result, the claim held by a "shareholder" is really a bond with a face value of $Y_{0}$ and a perpetual maturity. If we make the lower bound stochastic rather than determinate, then shareholders will not pay more than the lowest possible value of the relevant distribution, and, recursively, we end up with either a debt claim or a claim worth nothing at all. In short, firms with a shareholder who owns more than 50 percent but less than 100 percent of the equity could not exist.

This is not what we observe. Some features of the institutional landscape-legal rules, extralegal norms, contractual innovations, or all of the above - have made concentrated ownership possible. Although Bebchuk and Kahan do not ask what these institutional features are, their identification is a critical issue for those studying corporate governance. Holderness and Sheehan (chap. 5 in this volume) argue by process of elimination that legal constraints (particularly the fiduciary duties required of majority shareholders) are important, noting shareholders' disinclination to insist on explicit contractual protections.

We might also gain some insight by noting that the freezeout puzzle is a mirror image of the new-issue puzzle. A new issue of stock creates an adverse selection problem because the majority's desire to sell is evidence that the offering price is too high, just as the majority's desire to buy in a freezeout is evidence that the freezeout price is too low. By analogy to Bebchuk and Kahan's model, new issues should not sell at any price greater than the lowest possible valuation of the firm-presumably zero for realworld firms.

Loughran and Ritter (1995) present evidence that new issues (both initial public offerings and seasoned equity offerings) earn unexpectedly low long-term returns. Behavioral finance theorists might see this as evidence that purchasers are overly optimistic. Similarly, one might try to explain the failure of firms with concentrated ownership to trade at a discount to firms with diffuse ownership as evidence of overoptimism. If we accept these views, the existence of large public equity markets is a consequence of cognitive error.

An alternative perspective on new issues is that investment bankers act as information intermediaries, putting their reputation on the line to signal investors that the price is not too high. This provides still another 
avenue to explore in the case of freezeouts. Investment bankers act as information intermediaries, thereby giving fairness opinions. Although lawyers tend to view fairness opinions as a formality that protects directors against fiduciary liability, they also put the banker's reputation behind the claim that the price is not too low.

I would have preferred that Bebchuk and Kahan address explicitly the divergence between observed behavior and the predictions of the model. The paper does, however, provide an excellent starting point for future discussion of the problem of freezeouts and the legal and contractual responses.

\section{Reference}

Loughran, Tim, and Jay R. Ritter. 1995. The new issues puzzle. Journal of Finance 50:23-51. 
This Page Intentionally Left Blank 


\section{Economic Effects of Concentrated}

Corporate Ownership 
This Page Intentionally Left Blank 